\title{
A REALIDADE SOCIAL E MORAL DO DIREITO: UMA PERSPECTIVA DURKHEIMIANA*
}

Alexandre Braga Massella

A natureza das relações da obra de Durkheim com o direito oferece aos intérpretes diversas possibilidades de análise e de exploração. Submeter a testes empíricos proposições específicas de Durkheim sobre temas legais, como a hipótese relativa à evolução do direito penal (Schwartz e Miller, 1964), ou examinar as perspectivas que sua obra abre para entender a dimensão simbólica da pena (Garland, 1993; Smith, 2008) foram alguns dos caminhos explorados na literatura. Outra possibilidade, mais teórica, consiste em considerar o direito como um objeto entre outros da sociologia de Durkheim e tentar extrair um programa de pesquisa em sociologia jurídica, o que exige explicitar os esquemas explicativos propostos, as unidades de análise privilegiadas e os problemas de investigação abordados ${ }^{1}$. Trata-se, nessa perspectiva de análise, de explicitar a sociologia jurídica como uma ciência particular². De fato, a especialização das

\footnotetext{
* Agradeço a Brasilio Sallum Junior pelos comentários e sugestões.

1 Uma tentativa nesse sentido é a de Chazel (1991).

2 A sociologia jurídica foi talvez, junto com a sociologia da religião, a área mais estudada pelos durkheimianos. Entre os autores envolvidos no projeto temos
} 
ciências sociais é, para Durkheim, um passo crucial para a entrada delas no universo da ciência. A sociologia nada mais é do que o sistema das ciências particulares, embora Durkheim admita uma certa sociologia geral ${ }^{3}$.

Mas tornar as ciências particulares ramos da sociologia não é, para Durkheim, uma mera operação verbal. A denominação comum dada a elas comporta uma orientação metodológica e substantiva. A orientação substantiva mais fundamental é a da sociedade como causa determinante dos fenômenos sociais. Se uma sociologia jurídica deve estar imbuída de uma orientação sociológica nesse sentido, se os fatos sociais manifestam a natureza das sociedades, então o estudo do direito, pela sociologia, está articulado a um postulado com implicações claras para um tema jurídico como o da legislação, por exemplo: "a legislação é a codificação dos costumes populares" (Durkheim e Fauconnet, 1975, p. 152). Se conjugarmos a isso outros pressupostos substanti268 vos que vinculam a vida social a regras morais e ao direito como emanação destas, podemos concluir, com Schluchter, que o "direito é uma precondição da constituição da vida social e deve ser elucidado no quadro de uma teoria social geral e é apenas secundariamente um âmbito institucional ao qual esta teoria geral será aplicada" (Schluchter, 2002 p. 258). Assim, o direito não é apenas objeto de uma ciência especial - a sociologia jurídica - mas tema central de uma

P. Fauconnet, P. Huvelin, G. Davy, E. Lévy, M. Mauss, além, é claro, do próprio Durkheim. Vários colaboradores de Durkheim pertenciam ao mundo jurídico. P. Huvelin e E. Lévy eram professores de Direito, M. Halbwachs e F. Simiand tinham doutorado em Direito. G. Davy, M. Mauss e L. Gernet também tinham qualificações legais. No Année Sociologique, duas seções eram dedicadas a questões jurídicas. Uma delas, intitulada "Sociologia legal e moral", tratava da história do direito e de seu desenvolvimento legal. A outra, "Sociologia criminal e estatística moral", abordava o funcionamento das regras morais e legais. As obras resenhadas nessas seções continham material de diversas sociedades e períodos históricos. As áreas que ganharam mais destaque foram o direito familiar, o criminal, o contratual e o da propriedade (Vogt, 1983, pp. 177-78).

3 Para o lugar de uma sociologia geral na reflexão metodológica de Durkheim, cf. Borlandi (1998). 
teoria geral da sociedade. Estudar o direito não é estudar apenas um domínio da vida social, mas uma parte essencial da dimensão normativa de qualquer sociedade, a parte, na visão de Durkheim, mais consolidada.

A pertinência do direito para uma teoria geral da sociedade está articulada, de início, a uma tese de ordem metodológica, que não vamos abordar aqui. Registremos apenas que, em A divisão do trabalho social, Durkheim toma o direito como um símbolo que permite observar e mensurar um fenômeno que não é passível de observação direta: a solidariedade social. A solidariedade é um fenômeno interno e, como tal, impossível de observação direta, pois parte de sua referência diz respeito a processos que se passam na consciência: a união da imagem de ego com a imagem de alter (Durkheim, 1922, p. 26). Mas como a solidariedade está acompanhada por características objetivas (frequência de contatos, de relações com os outros ou com o grupo como um todo ${ }^{4}$ ), é possível substituir ao fato interno "um fato exterior que o simboliza e estudar o primeiro por meio do segundo" (Durkheim, 1922, p. 28). Esse fato exterior é o direito, que, como a moral, "é o conjunto de vínculos que nos ligam uns aos outros e à sociedade” (Durkheim, 1922, p. 393).

Assim, a entrada em cena do direito e, com isso, de uma certa concepção de direito, depende deste postulado: a "vida social, onde quer que exista de maneira durável, tende inevitavelmente a assumir uma forma definida e a se organizar e o direito não é outra coisa que esta organização

\footnotetext{
4 A solidariedade varia ao mesmo tempo e no mesmo sentido que a frequência de contatos entre os membros de um grupo (o que não quer dizer que seja a causa dessa maior frequência). A solidariedade, caso seja forte, "inclina fortemente os homens uns para os outros, os põe em contato frequente, multiplica as ocasiões em que se veem em relações" (Durkheim, 1922, p.29). O que se opõe à sociedade solidária assim entendida não é bem o conflito, mas a intermitência ou instabilidade de contatos e, no limite, o simples isolamento, a ausência de meio social, um estado que, se generalizado, significaria a desintegração da ordem social.
} 
no que ela tem de mais estável e preciso" (Durkheim, 1922, p. 29). O vínculo entre a dimensão estrutural das relações frequentes e próximas e a dimensão normativa das regras fundamenta a estreita relação entre o direito e a vida social.

É essa conexão entre o direito e a vida social e moral que pretendemos analisar. Discutiremos, em primeiro lugar, como a abordagem de Durkheim faz uso da noção de costumes para articular o direito e a vida social. Em seguida, exporemos dois estudos de sociologia jurídica que exploram a conexão proposta por Durkheim: o de R. Cotterrell sobre a jurisprudência e o de J. Ray sobre o direito civil. Por fim, examinaremos em que medida a noção de direito restitutivo consegue preservar a íntima conexão postulada por Durkheim entre o direito e a vida moral.

\section{Direito, hábitos e costumes}

A concepção de direito presente na visão que o torna a con270 solidação de algo subjacente e mais fundamental pode ser comparada, mas não identificada ${ }^{5}$, ao que Unger chama de direito costumeiro ou interacional:

[...] no sentido mais amplo, o direito é simplesmente qualquer modo recorrente de interação entre indivíduos e grupos, junto com o reconhecimento mais ou menos explícito por esses indivíduos e grupos de que tais padrões de interação produzem expectativas recíprocas de conduta que devem ser satisfeitas (Unger, 1976, p. 55).

A comparação vale porque essa concepção de direito interacional suscita um problema mais geral que parece presente em Durkheim, o de como explicar a passagem do que é recorrente ou habitual para o que é obrigatório. Os

\footnotetext{
5 Isso porque essa concepção tende a enfatizar o direito como um instrumento para coordenar as ações, tarefa que, como veremos, pode ser desempenhada sem que as normas se comprometam com juízos morais.
} 
dois elementos presentes nessa concepção - a regularidade fatual do comportamento e a ideia de uma ordem de direito - estão nela fundidos, o que a torna vulnerável à pergunta formulada por Parsons ao contestar a importância que Durkheim dá à conduta habitual: "em que parte do mecanismo do hábito encontrar o elemento de obrigação?" (Parsons, 1968, p. 321). O costume, para Durkheim, não é apenas uma maneira de agir habitual, mas também obrigatória para todos os membros da sociedade: "o que o distingue não é sua frequência maior ou menor, mas sua virtude imperativa. Ele não representa simplesmente o que se faz com frequência, mas o que deve ser feito" (Durkheim, 1975, p. 13). Nem toda conduta habitual é, assim, um costume. A preocupação de Durkheim é, aqui, estabelecer um critério objetivo para identificar um costume e não explicar a gênese da força imperativa que ele conteria. Cabe perguntar, porém, se o mero hábito teria essa consequência. Ao afirmar que o hábito, ao adquirir força, se transforma em regra de conduta (Durkheim, 1922, p. 357) ${ }^{6}$, Durkheim parece enfatizar a importância do hábito na gênese de uma regra imperativa. Isso poderia ser elaborado explorando-se os vínculos entre a frequência de uma conduta, a certeza assim gerada e o valor que damos à certeza e à previsibilidade das condutas. Mas Durkheim afirma também que o costume é mais do que o mero hábito. É de se supor, portanto, que certas práticas podem ser habituais sem por isso ganhar qualquer virtude imperativa. Uma outra forma de tratar a questão seria enfatizar o conteúdo da conduta e a importância de suas consequências como o fator decisivo na cons-

\footnotetext{
6 "Há certas maneiras de reagir umas sobre as outras que, achando-se mais conformes à natureza das coisas, se repetem com mais frequência e se tornam hábitos; depois os hábitos, à medida que adquirem força, se transformam em regras de conduta. O passado predetermina o futuro. Dito de outra forma, há uma certa distinção entre os direitos e os deveres que o uso estabelece e que acaba por se tornar obrigatória” (Durkheim, 1922, p. 357).
} 
tituição de um costume. Mas Durkheim contesta a tentativa de extrair do conteúdo de uma prática, como sua utilidade social, a virtude imperativa dela, ainda que a consideração da utilidade possa ser introduzida com a reflexão ${ }^{7}$. A forma propriamente durkheimiana de tratar a questão do caráter imperativo do costume exige desconsiderar a questão do conteúdo e enfatizar os processos psicológicos coletivos que conferem força imperativa a uma prática.

Mas é preciso distinguir a maneira como Durkheim elabora essa estratégia de outras aparentemente similares. $\mathrm{O}$ estudo do tema feito por E. Lambert (1903) e resenhado por Durkheim no volume VII do Année Sociologique (Durkheim, 1904, pp. 374-79) serve aqui de referência. Lambert reconstrói o problema formulado pela teoria romano-canônica, que decompõe o costume jurídico em dois elementos essenciais - o elemento externo, isto é, a repetição de atos uniformes que engendra um uso, e o elemento interno, o 272 sentimento de obrigação que imprime ao uso o caráter de necessidade jurídica - e analisa as soluções aventadas pela literatura jurídica e sociológica para entender esse elemento interno que transformaria o mero uso em regra jurídica. Apontar o consentimento tácito do conjunto dos cidadãos a uma regra que estaria contida nos atos usuais e que assim os legitimaria é uma primeira alternativa de análise do elemento interno. Na crítica de Lambert temos mais uma tentativa de justificação racional do que uma análise científica do costume. A tese teria sido elaborada com o objetivo de dar a essa fonte do direito a mesma origem e fundamento que aquela concedida à lei, a vontade do povo, identificada aí com o legislador (Lambert, 1903, pp. 122-23).

\footnotetext{
7 Assim, a regra que proíbe o crime e a punição que sua violação desencadeia não se explicam, em Durkheim, pela utilidade social. O efeito funcional da punição é espontâneo e não calculado e diz respeito à reafirmação automática das crenças e relações abaladas pelo crime. D. Garland denomina esse efeito de paradoxo da utilidade superior (Garland, 1993, p. 33).
} 
A visão da escola histórica alemã é a segunda alternativa, que critica a anterior de uma maneira que Durkheim, até certo ponto, aprovaria: o direito, e isso pode ser estendido para os costumes, não é uma criação artificial do espírito humano, mas "produto espontâneo do desenvolvimento social [...], enraizado no movimento contínuo da vida coletiva" (Lambert, 1903, p. 127). Esse reconhecimento da ação de forças naturais, de leis sociológicas, avalia Lambert, seria o elemento "original e fecundo" da escola histórica alemã, mas a tendência a exagerar o alcance dessa "verdade" teria deixado na sombra a colaboração "que cabe à iniciativa e à inteligência humanas na elaboração do direito e no jogo das leis do desenvolvimento social" (Lambert, 1903, p. 128). Assim, ao papel criador atribuído ao povo pela tese anterior, a escola histórica substitui um papel de "revelação e de constatação do direito". Uma suposta "intuição popular do direito, a percepção pela consciência da coletividade das regras jurídicas que, em um meio determinado, se impõem naturalmente, substitui o consenso popular tácito como elemento psicológico do costume" (Lambert, 1903, p. 128), isto é, a consciência ou instinto do povo tomam o lugar da vontade do povo. Lambert vê aí uma noção mística de consciência jurídica, que jamais teria sido precisada pelos adeptos da doutrina. A concepção de Durkheim não se confunde com essa tese, ainda que, para ele, os costumes e o direito expressem a consciência coletiva (sentimentos e crenças compartilhadas) e ainda que esta registre uma realidade subjacente, “a natureza das coisas". De fato, Durkheim contesta a existência de uma consciência jurídica da humanidade: isso seria admitir um direito natural "anterior à formação das sociedades e implicado, ao menos logicamente, na consciência moral do indivíduo" (Durkheim e Fauconnet, 1975 , p.157).

Uma terceira alternativa apontada por Lambert extrai o elemento interno não mais da suposta consciência popu- 
lar, mas de um conjunto de individualidades que, por meio de um ato de vontade, manifestaria a intenção de imprimir caráter jurídico a determinada prática usual. O interesse da crítica de Lambert a essa alternativa está em sua ênfase na dimensão conflituosa da vida social, ênfase que prefigura um tipo de crítica que será usual dirigir a Durkheim. A tese, em sua visão, só seria plausível se admitíssemos que no mundo moderno, em que o regime do costume não mais prevalece, ocorreu uma "transformação radical na natureza psicológica do homem” (Lambert, 1903, p. 137). Seu raciocínio explora o fato de que os conflitos, na vida jurídica contemporânea, não se resolvem espontaneamente por atos recíprocos de abnegação, por concessões mútuas, mas exigem a intervenção de uma autoridade. Fazer da aceitação unânime de um princípio jurídico a fonte do costume seria postular algo irreal, ao menos na sociedade contemporânea. Ora, pergunta-se Lambert, teria sido diferente em 274 uma espécie de "idade de ouro da humanidade"? Talvez na lenda, responde ele, mas não na história, pois não haveria na história "vestígios dessa harmonia mística da vontade de onde nasceria o costume. Nessas épocas de barbárie o homem era menos inclinado do que hoje a sacrificar espontaneamente parte de seus interesses pessoais para respeitar os interesses contraditórios de seus semelhantes" (Lambert, 1903, p. 138). Ora, a ideia de que a vida social, em condições normais, gera disposições altruístas que levam ao sacrifício mútuo dos interesses pessoais é cara a Durkheim. E não seria preciso, para tornar isso plausível, postular uma "transformação radical na natureza psicológica do homem". Há formulações de Durkheim a respeito das fontes do conflito social e das bases de sua superação que se pretendem válidas para qualquer tipo social. Os conflitos de interesse estão presentes tanto nas sociedades do passado como na sociedade moderna, já que as bases para uma conduta egoísta e, portanto, na visão de Durkheim, conflituosa estão 
presentes em qualquer tipo social. Há uma base para a individualidade e, portanto, para a conduta egoísta ${ }^{8}$ que não depende do tipo social. O mundo das "sensações internas e externas" é uma esfera da vida psíquica que varia de um homem a outro e pertence a cada um. É essa circunstância que torna "exagerada", na visão de Durkheim, a conclusão de que mesmo em uma situação em que a consciência do indivíduo é quase toda invadida pela consciência coletiva ela seria toda altruísta. Da mesma forma, seria equivocado concluir que, porque a consciência coletiva se retraiu no mundo moderno, a orientação egoísta da conduta se tornou maior no conjunto da vida. É este, pelo menos, o esforço de Durkheim ao tentar mostrar que há uma moralidade intrínseca à cooperação envolvida na divisão do trabalho. Dito de maneira geral, a ideia de Durkheim é a de que egoísmo e altruísmo estão presentes "desde o início" em todas as consciências humanas (Durkheim, 1922, p. 175). Mas se, por um lado, a "aceitação unânime" das regras esbarra nas divergências individuais, por outro, a mera existência de uma vida social coesa parece garantir, sem mais, a superação dessas divergências. A vida social, em condições normais, modera o egoísmo e gera disposições para "sacrifícios mútuos" (Durkheim, 1922, p. 207). Aquilo que para Lambert só seria plausível se postularmos uma "idade de ouro da humanidade" é, para Durkheim, um dado da vida social em condições normais.

O que mais interessa a Durkheim no direito costumeiro seria sua suposta origem inconsciente. É certo que é difícil pensar que normas emerjam, mesmo no direito costumeiro, sem a intervenção da agência humana, quer esta assuma a forma oficial, quer a forma de processos sociais como deliberação, consenso ou aceitação. Autores que defendem

\footnotetext{
8 "Cientificamente, uma conduta é egoísta na medida em que é determinada por sentimentos e representações que nos são exclusivamente pessoais" (Durkheim, 1922, p. 175).
} 
a natureza costumeira do direito sustentam que a necessidade de mecanismos para especificar as normas não necessariamente anula a natureza costumeira, no sentido amplo de íntima conexão com as práticas sociais, das normas (Webber, 2009). Resta aberta a questão da força imperativa das normas costumeiras. O raciocínio de Durkheim para explicar a autoridade das regras morais é bem conhecido: sendo regras feitas para a sociedade e pela sociedade, as regras morais se beneficiam da autoridade e do prestígio que a sociedade tem em relação ao indivíduo (Durkheim, 1992, pp. 74-76). O mesmo raciocínio seria aplicável às regras do direito se, como pensa Durkheim, as ideias morais são a alma do direito, e a autoridade de um código vem da autoridade dos ideais morais que ele expressa em fórmulas definidas (Durkheim, 1970, p. 150).

Nem mesmo a maior presença da atividade legislativa consciente no direito moderno nos autoriza, segundo 276 Durkheim, a abrir mão da íntima interdependência entre o direito e a vida social. Por exemplo, a articulação, pelo direito, de ideais como liberdade, autonomia e justiça não se deve ao reconhecimento de uma suposta fundamentação racional a priori do direito, mas à pressão da consciência coletiva, verdadeira autora de tais ideais ${ }^{9}$. A legislação eficaz reflete os valores morais vigentes na sociedade e não seria, portanto, uma fonte de direito que anula as fontes provenientes da vida social. No entanto, Durkheim não considera que o costume seja, nas sociedades complexas, uma fonte produtiva de direito como teria sido outrora (Durkheim, 1904, pp. 374-79) e nem mesmo na forma de jurisprudência, que é a visão proposta por Lambert, para quem o costume é produto da prática jurídica, sendo, portanto, criação consciente dos magistrados por meios das sentenças que decidem casos.

9 Para um tratamento durkheimiano do tema, cf. Davy (1922). 


\section{Jurisprudência e codificação}

A íntima conexão entre o direito e a vida social postulada por Durkheim parece presente justamente na atividade jurisprudencial, especialmente na common law inglesa, conforme a aproximação proposta por R. Cotterrell. Isso porque a visão assistemática que Durkheim tem da moral, em que as práticas morais não são deduzidas de princípios filosóficos gerais, mas referem-se a circunstâncias concretas que levam em conta os fatos relevantes (Cotterrell, 2000, p. 12), tem uma correspondência com o tipo de sistematização presente na common law, que integra ao direito a "experiência moral" de uma comunidade. Conforme a reconstrução de Cotterrell, o direito costumeiro procura um difícil equilíbrio entre a sensibilidade aos detalhes dos casos particulares e as aspirações à universalidade e à generalidade, entre o concreto e o abstrato, o assistemático e o sistemático, a flexibilidade e a fixidez, mas aproximando-se mais dos primeiros termos da tensão do que dos segundos. Embora não favoreça a sistematização lógica da lei além das necessidades da tomada de decisão prática, o método da common law encoraja o que Cotterrell chama de "sistematização cultural": ele permite que as ideias morais presentes nos diversos contextos práticos sejam elaboradas de forma relativamente precisa, ainda que provisória. O juiz, segundo a concepção clássica da common law, "expressa a essência da experiência moral da comunidade, destilando-a na forma de decisões 'sábias'”. A sabedoria em questão não significa a capacidade de elaboração lógica de conceitos abstratos, mas a habilidade para expressar com precisão as intuições morais populares e extrair delas princípios gerais para a orientação prática futura e a interpretação dos casos concretos (Cotterrell, 2000, p.11). Dessa maneira, estaríamos distantes de uma casuística que apenas acumula os casos decididos, mas também não se perderia o contato com as intuições morais. Apesar de sua linguagem técnica e da garantia fornecida pelo Estado, o direito, na perspec- 
tiva da common law, extrai sua autoridade da moralidade da comunidade. Porém, e daí a tensão mencionada antes, o direito fornece estruturas relativamente gerais e universais de regulação normativa. Ora, na medida em que as práticas morais são, segundo Durkheim, assistemáticas, isto é, não são um corolário de princípios filosóficos gerais, mas produto da elaboração das circunstâncias concretas e dos fatos relevantes em jogo, a incorporação da moralidade no direito não será feita sem uma tensão entre, de um lado, "o esforço de criar o direito como um sistema objetivo de aplicação geral e, de outro, o esforço de refletir a relativa especificidade das práticas e juízos morais" (Cotterrell, 2000, p. 13). A contraposição entre a common law e o direito positivo é clara. Além de afirmar sua separação analítica da moralidade, o direito positivo vê no direito um conjunto sistemático de regras estabelecidas de forma deliberada que fornece, na interpretação liberal moderna, regras no interior das quais diversas 278 moralidades privadas podem coexistir. A concepção clássica da common law, insiste Cotterrell, não se refere exatamente a regras, "mas a princípios flexíveis que ganham significado na interpretação prática em contextos específicos” (Cotterrell, 2000 , p. 15$)^{10}$.

Mas se o caráter assistemático da concepção clássica da common law é um caso especialmente favorável para a proximidade postulada por Durkheim entre o direito e a moral, o que dizer do caso que poderíamos situar na extremidade oposta, isto é, do direito que é fruto da atividade legislativa consciente e que está sistematizado e codificado? O que essa

\footnotetext{
${ }^{10}$ Cotterrell reconhece que essa concepção da common law, que pressupõe uma comunidade moralmente unificada como base do direito, não pode ser aplicada sem mais às condições modernas, em que esse pressuposto parece pouco plausível. Para satisfazer as exigências contemporâneas, é preciso repensar essa ideia de comunidade e reconhecer que a lei não pode ser vista hoje como relacionada a uma única comunidade moralmente unificada. A lei se relaciona a diferentes tipos de comunidade moral, refletindo diferentes tipos de relações sociais, tema que o autor elabora explorando recursos conceituais fornecidos por M. Weber (Cotterrell, 2000, pp. 20-21).
} 
outra forma de expressão do direito implica para as relações entre o direito e a moral? Esse tipo de direito parece comportar um alto grau de racionalização, parece orientado por princípios abstratos e está, assim, distante do caráter assistemático do universo moral. Consideremos o caso da codificação, para examinar de que maneira um estudo inspirado em Durkheim tenta enfrentar o tema preservando os vínculos do direito positivo, fruto da atividade legislativa deliberada, com uma realidade mais fundamental, resultado de uma atividade coletiva e impessoal. Mas, nesse caso, a realidade mais fundamental não nos remeterá a um mundo extralegal: é o próprio universo jurídico que se desdobra em uma parte mais racional e deliberada e uma parte mais coletiva e impessoal, sendo esta última tomada como a mais fundamental.

Durkheim considera que o direito escrito e codificado surge quando há contestação ou dificuldades de interpretação no direito costumeiro (Durkheim, 1922, p. 41), mas ele não vai além desta consideração. J. Ray ${ }^{11}$, em estudo sobre a estrutura lógica do Código Civil Francês de 1804 (Ray, 1926), dedicado a um de seus mestres, Durkheim, considera o Código como um "fato social e intelectual", características que estariam estreitamente ligadas. Ray serve-se da sociologia e da lógica, perspectivas que poderiam ser conjugadas porque o fato intelectual da sistematização seria próprio de um determinado tipo de sociedade. Se a concepção de um Código uniforme e sistemático parece tributária de um espírito racionalista, não devemos esquecer, enfatiza Ray, a ampla influência que o respeito à história e à tradição exerceu na redação. Seria a rigor um engano imaginar que o Código foi escrito por racionalistas puros e que se trata de uma obra de ideologia abstrata. A verdade, diz Ray, é que os redatores tiveram um sentimento vivo do necessário respei-

${ }^{11}$ Jean Ray contribuiu com resenhas para o Année Sociologique de 1898 a 1913 e na nova série da revista entre 1925 e 1927. 
to aos costumes e do caráter arbitrário das doutrinas (Ray, 1926, p. 6). Mas não se trata apenas de ponderar o peso de tendências opostas na elaboração do Código. A própria formulação da oposição - obra da pura razão versus sentimento do valor das instituições consagradas pelo tempo - conteria um equívoco que dissimularia um fato capital. O papel da razão no direito não estaria, segundo Ray, devidamente representado nessa oposição. Ou acredita-se que a razão desempenha o papel de justificar instituições fundamentais como a família e a propriedade e, para criticar tais instituições, ataca-se a razão, ou, e este é o caso mais frequente, a razão é representada como uma espécie de força abstrata e vazia. Ora, sustenta Ray, "o papel da razão no Código é bem outro: ela não é solidária de determinadas instituições e também não é estranha ao conteúdo vivo e concreto da lei" (Ray, 1926, pp. 7-8). Ray dissocia, assim, o empenho racionalista da intenção de mudar as instituições e o restringe ao 280 papel de ordenar o universo legal já existente. Assim, há no trabalho de Ray a referência permanente a uma realidade mais fundamental que estaria subjacente ao Código Civil, mas essa realidade não é apenas a realidade social ou moral, mas também a realidade legal anterior ao Código, realidade que é produto de uma elaboração coletiva e impessoal.

E sequer esse trabalho de ordenação seria obra pessoal de um indivíduo. $\mathrm{O}$ fato de que, no mesmo momento, vários autores tenham se dedicado a isso sugere a ideia de uma necessidade ou gosto do tempo. Além disso, os "procedimentos empregados nada têm de novo e a codificação surge como o coroamento de uma evolução iniciada há muito tempo" (Ray, 1926, p. 8). A razão não é, assim, "inimiga da história", mas um dado da história. A intervenção da razão na sistematização do direito não representa uma força intrusa, mas uma emanação da vida das instituições. $\mathrm{O}$ estudo lógico e o estudo sociológico do direito se aproximariam (Ray, 1926, p. 9), pois os fatos lógicos são também fatos 
sociais, o que quer dizer que a análise da estrutura lógica do Código, das formas proposicionais das prescrições jurídicas, do uso de certas categorias é ao mesmo tempo uma descrição da forma da sociedade. De modo bem durkheimiano, Ray procura reduzir ao mínimo a presença do artifício e da iniciativa individual no Código Civil francês.

A função do legislador e, sobretudo, a do autor de um Código seria semelhante à função do juiz, ou seja, dizer o direito e não criá-lo, ponto que parece destoar do papel ativo atribuído por Durkheim ao "órgão governamental". Mas basta precisar o que Durkheim quer dizer quando acentua o papel criativo do órgão governamental para dissipar a possível divergência. As representações novas que o órgão governamental acrescenta ao "pensamento irrefletido" da massa não são arbitrárias; a clarividência desse órgão se deve apenas ao modo reflexivo e unificado com que elabora um maior número de informações sobre a sociedade. Tais condições organizacionais e cognitivas permitem a esse órgão descobrir o que é mais útil para a sociedade (Durkheim, 1950, p. 112). O novo e o original jamais se confundem, em Durkheim, com o arbitrário. Para Ray, assim como o direito de cada época não é o produto arbitrário da vontade do legislador, mas um "efeito necessário das circunstâncias", a codificação também seria produto de circunstâncias (Ray, 1926, p.10). A própria unidade de um texto que é a confluência de diversas tradições ${ }^{12}$ não teria sido forjada artificialmente na época da redação, mas já estava dada, restando apenas tomar consciência dela. Mesmo as inovações e as criações da jurisprudência no século XIX foram feitas sem prejuízo do respeito pelos textos legais. As construções jurisprudenciais que se opõem ao texto legal consistem em se servir de um texto contra outro, o que seria sinal do res-

$12 \mathrm{O}$ direito romano, o direito costumeiro, sobretudo o de Paris, as ordenanças reais e as leis da época intermediária (Ray, 1926, p. 15). 
peito pela autoridade do texto (Ray, 1926, pp. 19-20). O prestígio vinculado aos termos legais e a santidade, característica permanente e universal da lei, não estariam ligados apenas à autoridade social depositada na lei, mas também à sua estabilidade no tempo. E, caso seja levantada a objeção de que, na época da redação do Código, a fria análise e discussão de toda a regulamentação legal teria atingido o prestígio da lei, Ray aconselha a não exagerarmos esse fato, enfatizando mais uma vez que o Código foi, em geral, simplesmente a consagração de instituições e fórmulas antigas. O estilo do Código, seco, preciso, abstrato, também deve ser atribuído a uma concepção a respeito da linguagem jurídica que se formou aos poucos, nos meios próprios aos homens da lei, homens que, "se estavam um pouco distantes da vida", é porque faziam parte do corpo de especialistas e técnicos próprio de uma sociedade diferenciada e complexa ${ }^{13}$. O caráter técnico da linguagem jurídica seria, 282 assim, consequência inevitável da diferenciação, da complexidade para a qual o direito evolui. É certo que o caráter técnico do Código implicou o abandono de um ideal caro à época revolucionária, quando se proclamou a necessidade de elaborar códigos acessíveis a todos e, portanto, tão desprovidos quanto possível de caráter técnico. Na avaliação de Ray, esse ideal não era compatível com o grau de evolução social a que se chegou (Ray, 1926, p. 26). Mas nem nesse ponto Ray admite uma dissociação entre o direito e a tradição, pois a linguagem técnica das leis seria ela mesma obra de uma tradição, ainda que interna ao direito ${ }^{14}$.

${ }^{13} \mathrm{O}$ funcionamento do direito restitutivo, em oposição ao repressivo, por meio de órgãos especiais é brevemente aludido por Durkheim em A divisão do trabalho social (Durkheim, 1922, p. 81).

${ }^{14}$ Estamos aqui distantes da postura crítica que encontramos, por exemplo, em J. Bentham, que denuncia o caráter pomposo e cerimonioso das práticas legais e o uso de um jargão prolixo e distante da linguagem ordinária como instrumentos que fomentam uma atitude de humilde reverência à tradição, dificultando as reformas e o reconhecimento de que as leis são expressão da vontade humana e, como tais, modificáveis (Hart, 2001). 
As influências sociais que agem sobre o legislador não se resumem, na interpretação de Ray, à determinação de objetivos, sejam estes vagos ou precisos. É preciso levar em conta, para dimensionar bem essa influência, a presença de representações e tendências que atuam, nem sempre de forma explícita, na consciência do legislador. As disposições do Código Civil seriam a parte visível de algo mais fundamental que está oculto. Daí a dificuldade de percebermos esse "fato capital", pois todos nós "estamos imersos no mesmo oceano de representações e sentimentos" (Ray, 1926, p. 138). Um exemplo apresentado por Ray diz respeito às disposições relativas à família. Há no Código Civil um grande número de textos sobre a família, mas não encontramos nele quase nenhum dos princípios fundamentais sobre os quais repousa essa instituição e que permite a plena compreensão das disposições explícitas. A exposição legal “pressupõe, mas não formula, os princípios essenciais do parentesco entre nós" (Ray, 1926, p. 140), princípios que o direito sucessório aplica. Isso mostra todo o substrato de ideias às quais se vinculam as disposições esporádicas da lei. Assim, os recursos normalmente oferecidos ao intérprete da lei, como o raciocínio abstrato, as indicações de trabalhos preparatórios, os precedentes históricos ou as necessidades conscientes da sociedade contemporânea não são suficientes para compreender plenamente as disposições da lei. Para tanto, é preciso uma história geral do direito comparado, que, por sua vez, é parte de uma sociologia geral (Ray, 1926, p. 141).

Ray analisa ainda o Código Civil como expressão de uma ordem ideal desejada. O pensamento jurídico e os conceitos legais têm um aspecto construtivo, isto é, foram concebidos e impostos não com o objetivo de exprimir uma realidade previamente dada, mas com o objetivo de reger a atividade humana (Ray, 1926, p. 104). Mas essa construção não é artificial, pois o legislador deve se orientar pelos costumes e as necessidades da sociedade para a qual legisla. Assim, quando 
se trata de refletir sobre a natureza construtiva do Código, Ray não nos remete às inovações propostas pelo legislador, ou às forças sociais que reivindicam esta ou aquela inovação, mas ao que há de idealização no pensamento jurídico como tal, empregando a distinção de Durkheim entre juízos de realidade e juízos de valor (Durkheim, 2004, pp. 117-41). O juízo de valor "transfigura a realidade", mas não deixa de exprimir uma natureza, "a faculdade que o homem em sociedade tem, especialmente em épocas de exaltação coletiva, de criar ideais" (Ray, 1926, p. 109).

\section{Direito, solidariedade e ordem social}

O estudo do direito restitutivo, próprio à sociedade moderna, permite captar um determinado aspecto da sociedade, o das relações entre funções diferentes. O que Durkheim enfatiza aí é a moralidade que surge de nossa integração em grupos e, principalmente, das relações regulares entre 284 grupos e funções distintas. Esse direito fornece uma representação esquemática da vida social, pois muitas relações de dependência mútua só são reguladas por usos e regras não escritas (Durkheim, 1922, p. 119), e suas prescrições estão mais ou menos fora da consciência coletiva. Um problema que a visão de Durkheim sobre o direito restitutivo apresenta é justamente a conexão que este mantém com a moral, conexão que sustenta todo o estudo da divisão do trabalho. Ao afirmar que tudo o que exigimos, nas condições de uma sociedade regida pela divisão do trabalho, é que as "funções trabalhem juntas de uma maneira regular" (Durkheim, 1922, p. 97) e ao afirmar que as regras que governam as tarefas especializadas não possuem uma força e autoridade transcendentes, Durkheim estaria rompendo com seus próprios pressupostos, isto é, abrindo mão da tese de que o direito é uma forma de moralidade sancionada de forma organizada? De fato, enfatizar o direito como um instrumento para coordenar e facilitar as interações pode bem 
preservar sua natureza social, mas tende a fazer do direito um método de organização social que prescinde de acordos substantivos, como acordos em torno de ideais de justiça. A coordenação das ações pode se referir apenas à necessidade de regras que assegurem expectativas complementares e estáveis de conduta, algo que pode ser obtido mesmo entre indivíduos que pouco compartilham a respeito de ideais morais; a coordenação diz respeito à necessidade de regras comuns, mas pouco diz sobre o conteúdo destas (Webber, 2009). Na avaliação de Cotterrell, a moralidade própria ao direito restitutivo, tal como pensada por Durkheim, seria um "estranho tipo de moralidade". A injunção moral da modernidade exige que nos preparemos para desempenhar uma função específica e demanda que "sejamos gentis com nossos companheiros e justos, que realizemos nossas tarefas com eficiência, que trabalhemos para assegurar que todos desempenhem a função para a qual são mais capazes e que recebam uma recompensa justa por seu trabalho" (Durkheim, 1922, p. 404). Teríamos aí, segundo Cotterrell,

[...] menos um código moral para o indivíduo viver do que um código de gerenciamento para a sociedade - uma moralidade para a administração, uma injunção para assegurar que todos estejam em seus lugares apropriados, trabalhando normalmente. Tal moralidade do bom gerenciamento social é inteiramente diferente do tipo de moralidade que reside nos sentimentos da consciência coletiva (Cotterrell, 1999, p. 110).

Na leitura de Cotterrell, Durkheim recuperaria uma base moral para o direito moderno ao dar nova ênfase, após a Divisão do trabalho social, à liberdade e à dignidade do indivíduo como valores centrais. A moralidade desse culto ao indivíduo forneceria as bases dos modernos direitos legais, fundamentando esses direitos na sociedade e não no indi- 
víduo como ser isolado e dando sentido aos deveres, que não seriam apenas concessões necessárias aos outros indivíduos, mas elos que nos ligam à sociedade de forma ativa. Talvez seja exagerado considerar que o reconhecimento da necessidade de valores consensuais implicou, por parte de Durkheim, o abandono da perspectiva que ele mesmo adotou em A divisão do trabalho social, isto é, o abandono da ênfase em fatores morfológicos em favor de fatores ideais. Como aponta Watts Miller, a passagem em A divisão do trabalho social $^{15}$ que descaracteriza a moralidade do culto ao indivíduo pode ser lida como um recurso retórico apenas, pois é difícil acreditar que Durkheim adotou momentaneamente a ideia de um eu atomizado, atacada em todo o livro. O consenso em torno do ideal humano é, tanto quanto a divisão do trabalho, a base da coesão do mundo moderno ${ }^{16}$.

Uma outra tentativa de explicitar as fontes morais do direito restitutivo pode ser encontrada em I. Macneil. Além 286 do ethos individual, a consciência coletiva teria, na sociedade moderna, quatro fontes: uma consciência da dependência em relação à tecnologia e ao capital, o que faria com que poucos estivessem dispostos a combater a ordem social (tal combate dependeria da crença de que esta ordem é uma catástrofe para o ser humano); os elementos de consci-

\footnotetext{
15 "Temos pela dignidade da pessoa um culto que, como todo culto forte, já tem suas superstições. Trata-se, assim, se se quiser, de uma fé comum. [Mas], se ela é comum por ser compartilhada pela comunidade, é individual por seu objeto. Se ela orienta as vontades para um mesmo fim, esse fim não é social [...]. É da sociedade que ela extrai toda a força que possui, mas não é à sociedade que ela nos vincula: é a nós mesmos. Por conseguinte, ela não constitui um verdadeiro vínculo social" (Durkheim, 1922, p. 147).

${ }^{16}$ A rigor, na avaliação de Watts Miller, nem esse ideal bastaria para assegurar tal coesão, pois a divisão do trabalho e a própria natureza do ideal humano constituem uma fonte de opiniões substantivas conflitantes. Os ideais de justiça, liberdade e igualdade são, afinal, objeto de interpretações divergentes que precisam ser negociadas para gerar políticas coletivas momentaneamente consensuais. Seria essencial, assim, recorrer a outras coisas, ainda que estas tenham sua fonte básica na divisão do trabalho e no ideal humano, como, por exemplo, normas procedimentais de tolerância e uma identidade compartilhada (Watts Miller, 1996, p. 98).
} 
ência coletiva provenientes da própria divisão do trabalho, como o respeito pelos direitos de propriedade, reciprocidade e consenso nas relações contratuais; a moralidade do sacrifício, implícita em fatos como instituições sustentadas por doações ou o Estado de bem-estar social, que envolve um sistema de redistribuição em que alguns se sacrificam em favor de outros; o medo da sanção (Macneil, 2009, pp. 95-99). É bom dizer, porém, que seria difícil ajustar todos esses elementos na concepção durkheimiana de moral. $\mathrm{O}$ primeiro contém apenas uma resignação fatalista a uma situação de fato, não inspirando, portanto, um genuíno respeito moral; a moral do sacrifício não é, para Durkheim, o tipo da ação moral, isto é, se todos estiverem prontos a renunciar a seus interesses em favor do próximo, ninguém aceitará a renúncia do outro (Durkheim, 1992, p. 50); o medo, por fim, implica uma atitude calculadora em relação à sanção. Resta, como tipicamente durkheimiano, o segundo elemento, que tenta extrair uma moral da própria divisão do trabalho.

A tentativa de extrair, da divisão do trabalho, uma moral e o direito que consolida essa moral pode ser acompanhada na argumentação que Durkheim elabora para mostrar como a causa, a divisão do trabalho, produz o efeito, a solidariedade social. A moral e o direito são o produto normativo das condições estruturais em que se dão as trocas instauradas pela divisão do trabalho. Para entender a natureza desse produto normativo, é preciso considerar a crítica que Durkheim dirige às ideias de troca e de ordem social que ele atribui a H. Spencer.

$\mathrm{Na}$ análise utilitarista de Spencer ${ }^{17}$, a ordem gerada pela divisão do trabalho seria o resultado espontâneo das escolhas que os indivíduos fazem nas diversas esferas da ${ }^{17}$ Seguimos aqui, além da reconstrução feita por Durkheim da posição de H. Spencer,
a análise feita por Poggi (1972, pp. 168-70). 
vida social. As escolhas seriam orientadas pelo aumento do bem-estar do próprio indivíduo, cuja conduta seria restringida apenas pelos limites impostos pela liberdade do outro. A ordem prescindiria, assim, de medidas destinadas a regular o livre emprego pelos indivíduos de seus recursos para a obtenção de vantagens pessoais. Os fins teriam sua origem no próprio indivíduo e não em algo externo a ele. $\mathrm{O}$ modelo dessas relações é a troca e a estabilidade delas está garantida desde que as partes tenham interesse na continuidade das trocas. $\mathrm{O}$ cimento da sociedade é a vantagem mútua propiciada pelas trocas. Cabe, é claro, à lei impedir o emprego pelos indivíduos de meios como a fraude ou a violência, que alterariam o jogo normal dos interesses. A fixação na lei de sanções para essas condutas permite que os indivíduos levem em conta, nas estratégias que elaboram para atingir seus fins, as possíveis consequências que a aplicação das sanções acarretaria a eles. Assim, a ação da 288 sociedade teria como única meta impedir que os indivíduos tentem satisfazer seus interesses prejudicando os demais. A ação da sociedade seria apenas negativa, configurando o que Durkheim chama de solidariedade negativa. Como a expressão jurídica da troca é o contrato, a base da sociedade moderna seria o amplo sistema de contratos que consagra as trocas e vincula os indivíduos.

Essa visão, segundo Durkheim, é incapaz de explicar a estabilidade da ordem social. Se tudo o que tivéssemos fossem relações contratuais governadas pelo interesse e limitadas pela ameaça de sanções, a sociedade moderna seria muito instável. O interesse aproxima os homens de forma efêmera e só cria entre eles um vínculo exterior, que contém sempre um conflito latente ou adiado (Durkheim, 1922, p. 189). Durkheim se pergunta se a solidariedade orgânica seria algo tão precário e instável como a sociedade pensada conforme tais pressupostos. Ora, a natureza da intervenção da sociedade, no sentido de regular as relações 
entre as diferentes funções sociais, pode ser identificada e medida por meio do direito doméstico, do direito administrativo e, especialmente, do direito contratual, caso que, aparentemente, seria o mais favorável à tese de Spencer, pois esse direito pode ser interpretado como o coroamento de relações governadas apenas pelo interesse individual.

No caso do direito contratual, Durkheim explicita as condições que possibilitam o funcionamento das transações no mercado, impulsionadas pelo interesse. Spencer teria desconsiderado que as transações são mantidas de acordo com um corpo de regras obrigatórias que não são objeto de acordo entre as partes. As regras que regulam as relações contratuais não foram acordadas pelas partes, mas existem antes e independentemente desse acordo. Essas regras definem as condições de validade dos contratos, as consequências jurídicas de nossos atos contratuais e nos vincula a obrigações que, a rigor, não contraímos, porque não as deliberamos (Durkheim, 1922, pp. 189-94). O direito dos contratos exerceria então uma ação reguladora, predeterminando o que "devemos fazer e o que podemos exigir" quando, por decisão nossa, estabelecemos relações contratuais. A ação da sociedade não se limita a fazer executar o que foi acordado pelas partes, ela se faz presente também no conjunto de regras que não foi acordado pelas partes e que, de várias maneiras, regula as relações contratuais.

Para entender a relação aí envolvida entre o direito e a realidade social e moral, é preciso dimensionar bem o que Durkheim entende por troca, que é o processo simbolizado pelo direito contratual: trata-se de uma negociação descontínua, que não envolve nada além da troca de bens, ou de uma relação duradoura que envolve outras relações além da troca isolada ${ }^{18}$ ?

18 Tomamos a distinção de I. Macneil, que trata extensamente de suas implicações (Macneil, 2009). 
A questão é controversa entre os intérpretes. Na visão de Parsons, o que Durkheim obtém com a análise do direito contratual é apenas um insight empírico sobre a importância, para a estabilidade das relações, de regras normativas que controlam a conduta do indivíduo. A interpretação teórica desse "achado" empírico só teria começado a ganhar forma com o conceito de anomia, elaborado em $O$ suicídio, em que as normas regulam a conduta não só externamente, como condições para o estabelecimento de relações contratuais, mas "entram diretamente na constituição dos próprios fins dos atores" (Parsons, 1968, p. 382). Isso abre a possibilidade para uma nova concepção da relação do indivíduo com a norma. Em A divisão do trabalho social, Durkheim ainda pensaria a conformidade com a norma como um meio de evitar as consequências externas previstas na sanção, o que significa que a norma é um elemento das condições da ação que entra nos cálculos do ator. A superação dessa con290 cepção teria começado em O suicídio, com a transferência do elemento normativo para o mundo "interno" do ator. A atitude moralmente neutra do ator calculista em relação à norma dá lugar ao sentimento de obrigação moral, de respeito incondicional à norma. Isso propicia uma explicação mais satisfatória para a estabilidade das relações ${ }^{19}$.

Ainda segundo Parsons, se o direito contratual fornece a Durkheim um achado empírico fundamental para sua teorização posterior, ele também tende a dificultar uma abordagem não utilitarista da relação do ator com as normas, pois a instituição contrato está ligada a atividades predominantemente econômicas. Ora, diz Parsons, esta é a categoria de atividades em que "o elemento de regulação normativa está mais divorciado dos meios e fins imediatos da ação" (Parsons, 1968, p. 381). É como se a regulação normativa existisse

\footnotetext{
19 Munch (1981, p. 728) elabora uma interpretação similar, mas sem se comprometer com interpretações relativas a evoluções internas no pensamento de Durkheim.
} 
aí para conter os impulsos individuais e seus possíveis atritos dentro de certos limites, tanto em relação ao que pode ser acordado como em relação aos meios. O fundamento textual para essa interpretação está nas passagens em que Durkheim pressupõe o interesse como fator que orienta a conduta (Durkheim, 1922, p. 191) e na parte em que, ao criticar a ideia de Spencer de que a divisão do trabalho gera solidariedade por meio do acordo espontâneo dos interesses individuais, Durkheim aponta a precariedade dos elos baseados no interesse (Durkheim, 1922, pp. 180-81). Porém, é preciso considerar que uma das críticas que Durkheim dirige a Spencer é justamente a de que este reduz o contrato à troca. Ora, na visão de Durkheim, a troca não é todo o contrato, pois há também a boa harmonia das funções que cooperam. O direito contratual fixa as condições da cooperação por toda a duração das relações (Durkheim, 1922, p. 191) e sua intervenção é, por isso, de natureza positiva. Considerar a intervenção do direito contratual como negativa, como teria feito Spencer, é reduzi-lo ao ato momentâneo da troca. A troca, a rigor, seria apenas "a expressão superficial de um estado interno e mais profundo. Precisamente por ser constante, esse estado suscita todo um mecanismo de imagens que funciona com uma continuidade que a troca não possui. A imagem daquele que nos completa se torna, em nós mesmos, inseparável da nossa [...]; ela se torna, assim, parte integrante e permanente de nossa consciência" (Durkheim, 1922, pp. 27-28). Ao privilegiar passagens como esta, um intérprete como Watts Miller ressalta que o contrato não simboliza as relações mercantis transitórias em que os indivíduos usam uns aos outros como instrumentos de seus interesses (Watts Miller, 1996, p. 103), mas o conteúdo ético da divisão do trabalho, feito de regras que obrigam o indivíduo a fazer concessões e a levar em conta interesses superiores aos seus. $\mathrm{O}$ direito contratual não emana da parte mais superficial da divisão do trabalho, a troca descontínua, mas 
das relações mais duradouras que a troca supõe e que são instauradas pela divisão do trabalho (Watts Miller, 1996, p. 90). O direito não tem então apenas o papel negativo de minimizar os efeitos nefastos das ações egoístas, mas proporcionar canais para que o altruísmo possa se manifestar ${ }^{20}$. E, caso não se encontre isso no direito, o problema não reside no fato de que ele está destinado a regular apenas a camada mais superficial das trocas, mas em uma falha estrutural relativa às interações entre as funções. Nada disso implica negar a existência de conflitos e lutas: "o papel da solidariedade não é o de suprimir a concorrência, mas moderá-la” (Durkheim, 1922, p. 357). Além da disposição para as concessões gerada pelas relações duradouras, a predeterminação das obrigações mútuas impede que os conflitos se renovem constantemente. Ainda que a regulamentação não seja mais do que o equilíbrio entre forças em conflito, sua consolidação na lei impede que este ressurja a todo instante, seja porque não é fácil 292 alterar a lei, seja porque a forma legal do compromisso tem a virtude de conquistar o assentimento dos envolvidos.

***

A realidade mais fundamental que o direito simboliza tem várias dimensões, que espelham os diversos significados que o termo solidariedade assume em Durkheim. Uma dessas dimensões diz respeito ao concerto de esforços, à cooperação. Nas sociedades modernas, esse concerto envolve o desempenho de papéis diferenciados por indivíduos, a predeterminação da maneira pela qual devem cooperar e o ajuste dos papéis às inclinações individuais. Outra dimensão diz respeito ao aspecto moral da solidariedade. Ser solidário significa aqui levar em conta o outro, trans-

${ }^{20}$ É a interpretação da noção de regras organizacionais proposta por T. Campbell (1983). 
cender os impulsos egoístas na escolha das linhas de ação. Durkheim tende a fundir as duas dimensões, pois considera que a cooperação, quando associada a relações frequentes e contíguas, tende a gerar regras de teor moral. Mas a distinção das dimensões lembra que o direito pode ser vinculado a uma realidade mais fundamental que é social, mas não necessariamente moral. A coordenação das ações depende apenas de regras que garantam expectativas complementares e estáveis de conduta, prescindindo, portanto, de regras imbuídas de moralidade. A realidade mais fundamental pode ser ainda, como vimos no estudo de J. Ray, a própria tradição jurídica, feita de fórmulas, conceitos, categorias e que ganha expressão sistematizada em um código.

Por ser a emanação de algo que é mais fundamental do que ele - práticas sociais, moral, costumes, tradições, representações coletivas -, o direito é uma via de acesso privilegiada ao estudo dos fatos sociais. A possibilidade que oferece à "observação" o torna um meio para o estudo do que está subjacente a ele. $\mathrm{O}$ direito, suas regras, sanções e classificações constituem, assim, o meio empregado por Durkheim para articular, de forma concreta, a sua visão sobre a solidariedade social e evitar um discurso abstrato baseado em supostas inclinações da natureza humana. Isso exige um trabalho teórico sobre o direito, único modo de extrair, desse "símbolo" visível da sociedade, as pistas para compreender a natureza e as formas das relações sociais. É o trabalho teórico sobre esse ponto de apoio "ao alcance do observador" que oferece também ao crítico das teses de Durkheim a oportunidade de contestá-lo armado de uma interpretação que também torne visível, mas de outra maneira, o símbolo visível da solidariedade. Desde, é claro, que se aceite o direito como indicador de algo mais fundamental, a solidariedade social, ponto de partida que desafia a crença comum de que há, de um lado, as regras do direito, e, de outro lado, as práticas efetivamente adotadas. 


\section{Alexandre Braga Massella \\ é professor do Departamento de Sociologia da Faculdade de Filosofia, Letras e Ciências Humanas (FFLCH) da Uni- versidade de São Paulo (USP).}

\section{BIBLIOGRAFIA}

BORLANDI, M. 1998. "Durkheim, les durkheimiens et la sociologie générale”. Année Sociologique, v. 48, n. 1, pp. 27-65.

CAMPBELL, T. 1983. The left and rights. London: Routledge \& Kegan Paul. CHAZEL, F. 1991. "Émile Durkheim et l'élaboration d'un 'Programme de Recherche en Sociologie'”. In: CHAZEL, F.; COMMAILLE, J. (orgs.). Normes juridiques et régulations sociales. Paris: LGDJ.

COTTERRELL, R. A. 1999. Émile Durkheim: Law in a moral domain.

Edinburgh: Edinburgh University Press. 2000. "Common law approaches to the relationship between law and morality". Ethical Theory and Moral Practice, v. 3, n. 1, pp. 9-26.

DAVY, G. 1922. Le droit, L'idéalisme et L'expérience. Paris: Félix Alcan.

DURKHEIM, E. 1904. "Compte rendu de E. Lambert, La fonction du droit civil comparé”. Année Sociologique, v. 7. 1922. De la division du travail social. Paris: Félix Alcan. 1950. Leçons de sociologie. Paris: Presses Universitaires de France. . 1970. "Sociologie et sciences sociales" In: DURKHEIM, E. La science sociale et l'action. Paris: Presses Universitaires de France. 1975. "Introduction à la sociologie de la famille". In: KARADY, V.

(org.). Textes 3. Fonctions sociales et institutions. Paris: Les Éditions de Minuit. . 1988. Les règles de la méthode sociologique. Paris: Champs Flammarion. . 1992. L'éducation morale. Paris: Presses Universitaires de France. 2004. Sociologie et philosophie. Paris: Presses Universitaires de France.

DURKHEIM, E.; FAUCONNET, P. 1975. "Sociologie et sciences sociales". In: KARADY, V. (org.). Textes 1.Éléments d'une théorie sociale. Paris: Les Éditions de Minuit.

GARLAND, D. 1993. Punishment and modern society. Chicago: University of Chicago Press.

HART, H. L. A. 2001. Essays on Bentham. Oxford: Clarendon Press.

LAMBERT, E. 1903. La fonction du droit civil comparé. Paris: V. Giard e E. Brière.

LENOIR, R. 1993. "Le droit et ses usages". In: BESNARD, P.; BORLANDI, M.; VOGT, P. (orgs.). Division du travail et lien social. Paris: Presses Universitaires de France. 
MACNEIL, I. R. 2009. O novo contrato social. Rio de Janeiro: Elsevier. MUNCH, R. 1981. "Talcott Parsons and the theory of action. The structure of the kantian core”. American Journal of Sociology, v. 86, n. 4, pp. 709-39.

PARSONS, T. 1968. The structure of social action. New York: The Free Press.

POGGI, G. 1972. Images of society. Stanford: Stanford University Press.

RAY, J. 1926. Essai sur la structure logique du Code Civil français. Paris: Félix Alcan.

SCHWARTZ, R. D.; MILLER, J. C. 1964. "Legal evolution and societal complexity”. The American Journal of Sociology, v. 70, n. 2, pp. 159-69.

SCHLUCHTER, W. 2002. "The sociology of law as an empirical theory of validity”. Journal of Classical Sociology, v. 2, n. 3, pp. 257-79.

SMITH, P. 2008. Punishment and culture. Chicago: University of Chicago Press.

UNGER, R. M. 1976. Law in modern society. New York: The Free Press.

VOGT, W. P. 1983. "Obligation and right: the durkheimians and the sociology of law". In: BESNARD, P. (org.). The sociological domain: the durkheimians and the founding of French sociology. Cambridge: Cambridge University Press.

WATTS MILLER, W. 1996. Durkheim, morals and modernity. Montreal:

McGill-Queen's University Press.

WEBBER, J. 2009. "The grammar of customary law”. McGill Law Journal, v. 54, pp. 579-626. 


\section{A REALIDADE SOCIAL E MORAL DO DIREITO: UMA PERSPECTIVA DURKHEIMIANA}

\section{ALEXANDRE BRAGA MASSELLA}

Resumo: $\mathrm{O}$ artigo explora a ideia de Durkheim de que a instituição Direito deve ser entendida à luz de uma realidade mais fundamental: a realidade social e moral. São tratadas a concepção de direito aí envolvida e as diversas dimensões dessa realidade mais fundamental, especialmente as que foram elaboradas por autores que se inspiraram em Durkheim. Por fim, é tratado o problema que o direito chamado por Durkheim de restitutivo apresenta para a sua própria tese a respeito dos vínculos do universo jurídico com a realidade social e moral.

Palavras-chave: Durkheim; Direito; Sociologia do Direito; Moral; Integração Social.

\section{THE MORAL AND SOCIAL REALITY OF LAW: A DURKHEIMIIAN PERSPECTIVE}

Abstract: This paper investigates Durkheim's idea that Law should be understood by means of the study of a more basic reality: moral and social reality. The article approaches Durkheim's conception of Law and the diverse aspects of this more basic reality, especially the aspects treated by authors inspired by Durkheim. The final part of this paper is devoted to the problem that restitutive Law presents for Durkheim's thesis about the ties between the juridical world and the social and moral reality.

Keywords: Durkheim; Law; Sociology of Law; Moral; Social Integration. 